\title{
NOVA VERSÃO DO SISTEMA DE AVALIAÇÃO DE TERRAS - SIAT
}

\section{GILBERTO J. GARCIA ${ }^{1}$, SERGIO L. ANTONELLO ${ }^{2}$, MÔNICA G. M. MAGALHÃES ${ }^{3}$}

RESUMO: O SIAT é um sistema especialista para Avaliação de Terras derivado do MicroLEIS - Land Evaluation Information System desenvolvido na Espanha. Na primeira versão, as 12 variáveis foram adaptadas e ajustadas para condições tropicais, assim como a estrutura do programa e o banco de dados. Os testes de campo mostraram que os melhores resultados foram obtidos para escalas próximas de 1:100.000. Nesta segunda versão, os intervalos das variáveis foram redefinidos e uma interface de comunicação com o SIG IDRISI foi introduzida, permitindo a troca de dados entre os dois programas. Outra modificação importante foi a adoção de uma equação para calcular a erosividade no lugar de mapa apresentado no Manual do Usuário. Os testes de campo mostraram que o uso do SIAT é agora mais funcional, com melhor resolução, permitindo trabalhar com escalas em torno de 1:50.000, além de ser adaptável para todo o território brasileiro. A versão do SIAT pode ser obtida pelo endereço www.rc.unesp.br/igce/ceapla/biblioteca/softwares/siat.html.

PALAVRAS-CHAVE: avaliação de terras, capacidade de uso, SIG.

\section{LAND EVALUATION SYSTEM - SIAT - ADAPTED VERSION}

\begin{abstract}
The SIAT is a specialist system for Land Evaluation derived from the MicroLEIS Land Evaluation Information System developed in Spain. In its first version the 12 variables were adapted and adjusted for tropical conditions as well as the program structure and databank. In that time the field tests showed that the best results were obtained for scales near 1:100.000. In this second version the ranges for each variable were redefine and a communication interface with the GIS IDRISI was introduced, which allowed the exchange of data between the two programs. Another important modification was the adoption of an equation to calculate the erosivity in place of the original map as part of the User's Guide. The field tests showed that the use of the SIAT is now much more functional and presents a much better precision enabling the use of scales around 1:50.000, besides it can be adjusted all over the Brazilian territory. The SIAT V.1.4 can be downloaded from www.rc.unesp.br/igce/ceapla/biblioteca/softwares/siat.html.
\end{abstract}

KEYWORDS: land evaluation, land suitability, GIS.

\footnotetext{
${ }^{1}$ Eng ${ }^{-}$Agrônomo, Prof. Titular, Departamento de Planejamento Territorial e Geoprocessamento, UNESP, Rio Claro - SP, Fone: (0XX19) 3534.7862, gilberto@rc.unesp.br

2 Analista de Sistemas, M.Sc., Centro de Análise e Planejamento Ambiental, UNESP, Rio Claro - SP, sergio@ rc.unesp.br

${ }^{3}$ Analista de Sistemas, Doutor, Centro de Análise e Planejamento Ambiental, UNESP, Rio Claro - SP, monica@rc.unesp.br

Recebido pelo Conselho Editorial em: 18-2-2003

Aprovado pelo Conselho Editorial em: 25-5-2005
} 


\section{INTRODUÇÃO}

O Brasil, pelas dimensões continentais, apresenta problemas ambientais variados, sendo a degradação dos solos um dos principais. A classificação de terras para fins agrícolas é, provavelmente, o mais importante fator no planejamento territorial de uma região. Essa classificação eminentemente técnica trata da previsão do comportamento dos solos sob manejos específicos e sob certas condições ambientais (STELLE, 1967).

As duas principais classificações interpretativas de terras para fins agrícolas são:

Capacidade de Uso das Terras: é um sistema generalista, qualitativo e que leva em conta as limitações das terras. Baseia-se nas combinações de efeito do clima, características físicas e químicas do solo e aspectos de relevo, que limitam seu uso agrícola ou ainda os predispõem aos riscos de degradação. Originalmente desenvolvido pelo Serviço de Conservação do Solo dos EUA, foi sumarizado por KLINGEBIEL \& MONTGOMERY (1961). No Brasil, foi melhorado e divulgado por LEPCH et al. (1983).

Aptidão Agrícola das Terras: sistema baseado na melhor utilização das terras. As classes de aptidão agrícola representam um agrupamento de terras cujo conjunto de qualidades e limitações lhe confere condições semelhantes de utilização. Essa classificação leva em conta tanto fatores edafoclimáticos como tipos de culturas (RAMALHO FILHO et al., 1978).

Para os dois sistemas, o procedimento era trabalhoso e demorado, sugerindo, já na década de 1980, que a informatização seria fundamental na agilização dos processos de classificação. A literatura mostra que a utilização do geoprocessamento tem tido participação permanente no desenvolvimento de sistemas especialistas e no tratamento das informações com foco nessas classificações técnicas. Nesse caso, podem-se citar OLIVEIRA \& BERG (1985), ANDERSON (1987), BAUDRY (1989), LAI (1990), KEULEN (1990), ITC (1990), MacCLEAN (1993), KOFFLER (1993), GARCIA \& ESPINDOLA (2001) e FERNANDES et al. (2002).

Outra possibilidade é a utilização de SIGs - Sistemas de Informações Geográficas, cujas funções permitem a obtenção de resultados semelhantes. No entanto, nesse caso, o usuário deve dominar com segurança todas as fases presentes no SIG (ASSAD, 1998).

No caso dos sistemas especialistas, a base para o seu desenvolvimento é a modelagem matemática. Os sistemas mais modernos são associados a um SIG, permitindo facilidades na entrada, processamento e recuperação/espacialização das informações.

O sistema MICROLEIS - "Land Evaluation Information System" - foi desenvolvido para as condições ambientais de regiões mediterrâneas da Espanha (ROSA et al., 1992) e visa a avaliar a capacidade de uso das terras, sendo considerado um modelo empírico. Esse sistema foi adaptado às condições da região Sudeste brasileira por GARCIA \& ESPINDOLA (2001), oferecendo bons resultados para escalas próximas de 1:100.000.

O presente trabalho procura refinar esse sistema, com a introdução de modificações no modo como algumas variáveis são obtidas, com o objetivo principal de oferecer mapeamentos em escalas maiores.

\section{MATERIAL E MÉTODOS}

\section{Área de Estudo}

Na validação dos resultados dessa segunda versão, foi escolhida uma porção da bacia hidrográfica do Rio Jacaré-Pepira no Estado de São Paulo, conforme Figura 1. 


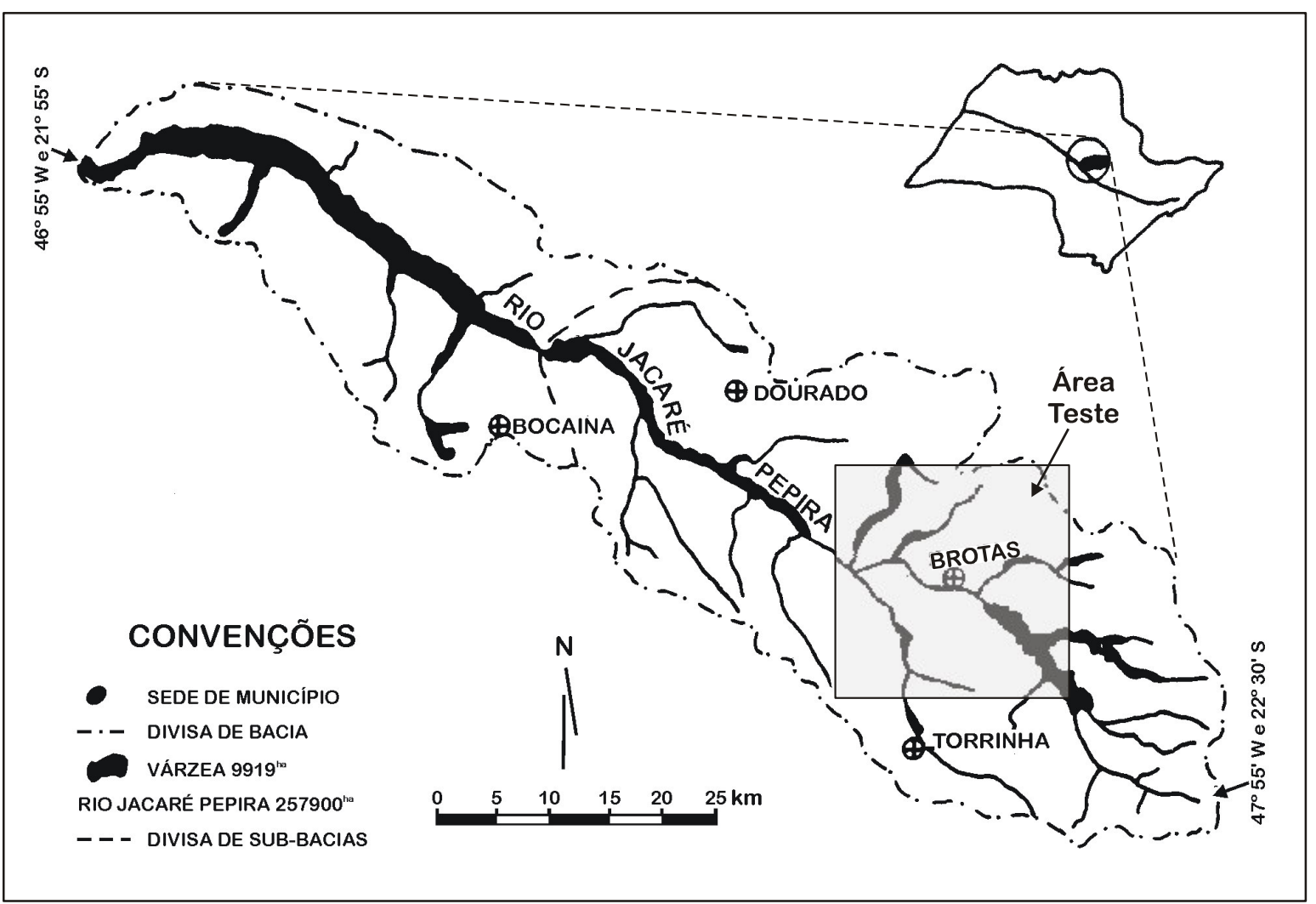

FIGURA 1. Localização da área de estudo.

\section{Características do Meio Físico}

De acordo com FULFARO et al. (1967) e SOARES (1976), a área apresenta a seguinte estrutura geológica:

\section{Grupo São Bento}

Formação Pirambóia: sucessão de camadas arenosas avermelhadas, geralmente fundos de vales.

Formação Botucatu: arenitos de granulação fina a média, uniforme, com maior ocorrência no médio curso do rio principal.

Formação Serra Geral: conjuntos de derrames tabulares de basaltos toleíticos entre os quais se intercalam arenitos, geralmente ocupando escarpas estruturais bem demarcadas.

\section{Grupo Bauru}

Formação Itaqueri: sedimentos areno-rudáceos que ocorrem no reverso da cuesta arenitobasáltica.

\section{Depósitos Cenozóicos}

São representados por superfícies de erosão e por depósitos sedimentares. Ocorrem nas planícies aluvionais do rio principal.

Geomorfologicamente, a área caracteriza-se por uma seqüência escalonada de patamares litoestruturais desenvolvidos sobre rochas sedimentares e basálticas em estruturas sub-horizontais. Os processos responsáveis pela gênese e evolução do relevo da área têm sua dinâmica vinculada a aspectos litoestruturais e antrópicos, conferindo grande variação ao relevo (FULFARO et al., 1967). 
Quanto aos solos, foram originalmente descritos por ALMEIDA et al. (1981) e PRADO et al. (1987). De acordo com o Sistema Brasileiro de Classificação de Solos (EMBRAPA, 1999), a nomenclatura é a seguinte:

Latossolos Vermelhos - textura argilosa: ocorrem geralmente em relevo suave ondulado, com distribuição predominante nas porções Leste e Oeste da bacia hidrográfica.

Latossolos Vermelhos - textura média: ocorrem em extensas áreas de relevo pouco movimentado, constituídos por colinas de topo ligeiramente aplainados e vertentes suaves e encostas com baixa declividade.

Latossolos Amarelos - textura média: apresentam-se em relevos suave ondulados, sobre arenitos das formações Pirambóia, Botucatu, Itaqueri e Depósitos Cenozóicos.

Nitossolos Vermelhos: aparecem principalmente nos fundos de vales; no caso da bacia do Rio Jacaré-Pepira, ao longo dos ribeirões Tamanduá, Peixe, Figueira e Bocaina.

Argissolos Vermelho-Amarelo - abrúptico: são encontrados no reverso das cuestas, em relevo suave a ondulado.

Neossolos Quartzarênicos: limitam-se às superfícies muito aplainadas, distribuídas na extremidade nordeste da bacia, entre Brotas e Dourado e também na extremidade noroeste.

Neossolo Litólico: estão associados a relevos movimentados em posições de encostas muito declivosas.

Solos Hidromorfóficos: formados a partir de sedimentos depositados nas partes mais baixas do relevo.

O clima da área é caracterizado, segundo a classificação de Köeppen, como do tipo Cwa subtropical úmido, com inverno seco e estação chuvosa de verão. As temperaturas médias anuais variam entre $18{ }^{\circ} \mathrm{C}$ e $22{ }^{\circ} \mathrm{C}$ e as precipitações médias anuais são de (SIGRH, 2004): Brotas (1.338 mm); Ribeirão Bonito (1.291 mm); Dourado (1.325 mm); Dois Córregos (1.286 mm); Torrinha $(1.319 \mathrm{~mm})$ e Itirapina $(1.340 \mathrm{~mm})$.

\section{Modelagem Ambiental}

Os modelos aplicados ao ambiente podem ser materiais: representam um sistema físico e são mais simples que o idealizado, e conceituais: são representações matemáticas do sistema físico. $\mathrm{O}$ modelo conceitual pode ser teórico: usa leis físicas para desenvolver um grupo de algoritmos para o sistema físico idealizado; ou empírico: usa dados observados para formular as relações do sistema. $\mathrm{O}$ modelo teórico pode ser dividido em determinístico: define o sistema físico como ele ocorre em um dado conjunto de eventos governados por um resultado identificável, e não-determinístico: expresso em termos probabilísticos ou estocásticos. O modelo determinístico pode ser dividido em concentrado: seus parâmetros e variáveis levam em conta o tempo, e distribuído: subdivide a área de estudo em elementos menores, mais homogêneos.

Na Figura 2, apresenta-se a classificação dos modelos, lembrando, como comenta TUCCI (1998), que, na prática, não existem separações tão nítidas entre modelos puramente distribuídos ou concentrados.

O MicroLEIS insere-se na categoria de modelo conceitual empírico, sendo um de seus componentes o módulo CERVATANA, o qual sistematiza as informações sobre as terras em quatro classes:

S1 - excelente capacidade de uso: terras com alta qualidade agroecológica, com nenhuma ou poucas limitações que restrinjam seu uso. 
S2 - boa capacidade de uso: apresentam algumas limitações de ordem topográfica, edáfica ou climática, restringindo o número de cultivos possíveis.

S3 - moderada capacidade de uso: apresentam limitações importantes, relacionadas com fatores topográficos, edáficos ou climáticos; as técnicas de manejo são mais difíceis de serem aplicadas e mantidas.

$\mathrm{N}$ - marginais ou improdutivas: aptas somente para pastagens ou produção florestal; essa classe inclui também as terras totalmente improdutivas.

Com exceção de Classe $S_{1}$, todas as outras se dividem em subclasses, com base em um ou mais dos seguintes critérios diagnósticos: Fator Relevo; Fator Solo: profundidade, textura, pedregosidade e/ou afloramentos, drenagem e salinidade; Fator Risco à Erosão: erodibilidade, declividade, densidade da vegetação e erosividade (Valor de R da USLE - Universal Soil Loss Equation); Fator Deficiência Bioclimática: grau de umidade do solo e risco de geadas.

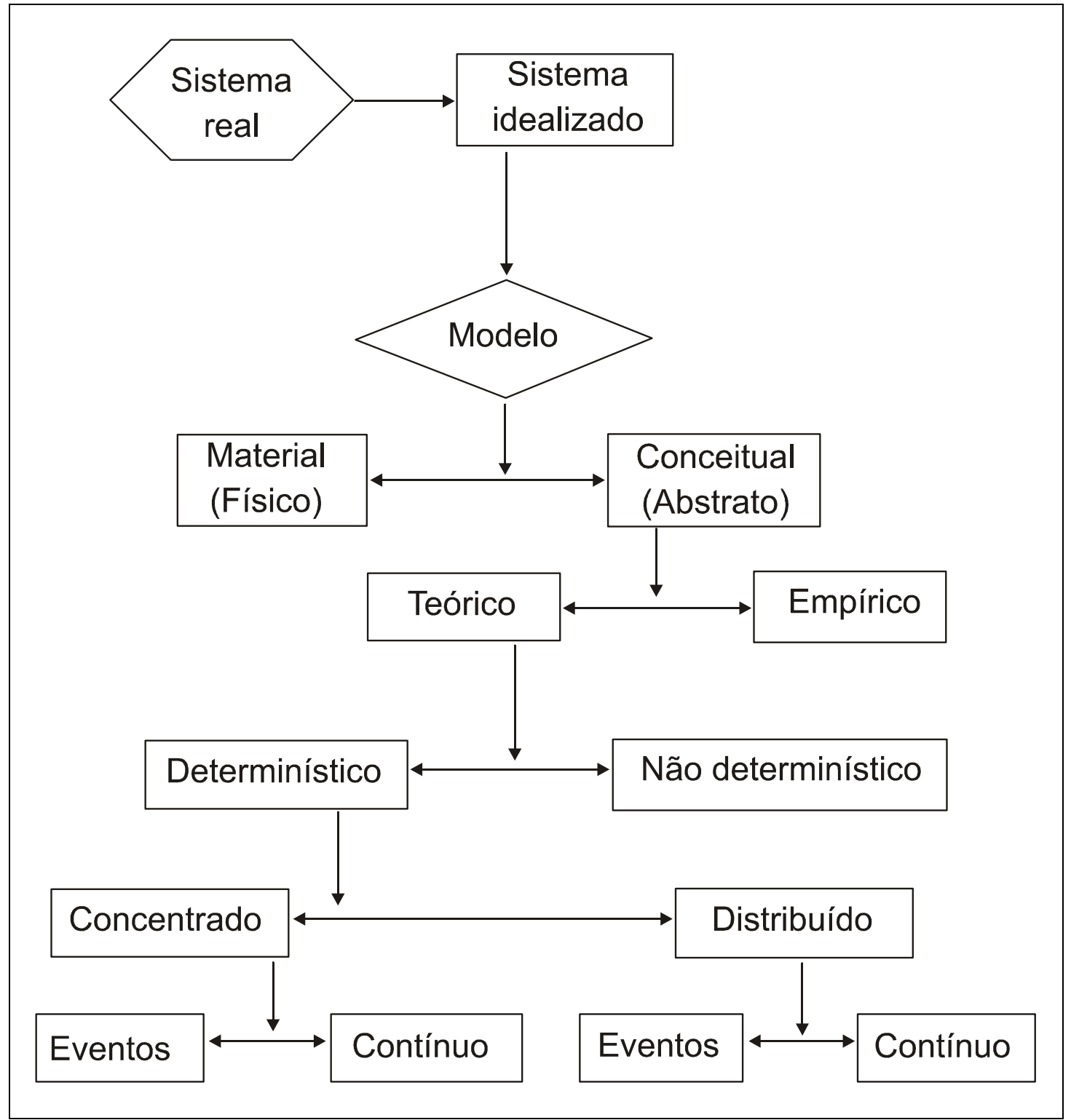

FIGURA 2. Classificação simplificada dos modelos (TIM, 1996). 


\section{Modificações introduzidas no MicroLEIS/CERVATANA para o SIAT V.1.0}

\section{Nos parâmetros quantitativos}

O módulo CERVATANA é caracterizado como matriz de pesos, ou seja, uma combinação linear ponderada de pesos conferidos a cada variável, segundo limites predeterminados.

Os critérios adotados para a adaptação do aplicativo foram os seguintes:

a) Embora a estrutura do CERVATANA permita a utilização de $n+1$ variáveis, optou-se por manter o número original (Tabela 1), no caso doze; relevância.

b) Substituição do parâmetro quando esse envolvesse dificuldade na obtenção ou quanto à

Nesse caso, as modificações foram as seguintes:

b.1. Substituição do cálculo do grau de umidade, de $\mathrm{Ih}=\mathrm{P} / \mathrm{ETP}$ por $\mathrm{AD}=\mathrm{P}-\mathrm{ETP}$, em que,
AD - água disponível;
$\mathrm{P}$ - precipitação, e
ETP - evapotranspiração.

b.2. Substituição da salinidade total por acidez $(\mathrm{pH})$. Sendo trabalho basicamente metodológico, desenvolvido no Estado de São Paulo, a acidez é muito mais relevante do que a salinidade, razão da substituição. Nas regiões semi-áridas, sem dúvida, a salinidade poderia ser mantida. Não haveria impedimento, no entanto, de se acrescentarem novas variáveis, ou seja, manter a salinidade e acrescentar a acidez.

c) Calibração dos intervalos de cada parâmetro empiricamente, tentativamente aproximando-se do padrão de referência, no caso, proposição de LEPSCH et al. (1983). Quando considerado necessário, aumentou-se o número de classes de um parâmetro. Em apenas um caso (Textura), isso aconteceu.

As modificações introduzidas aparecem na Tabela 1, ao lado dos parâmetros originais do sistema espanhol.

\section{Na estrutura do programa}

As modificações introduzidas no CERVATANA tiveram o objetivo de modernizar o sistema, aumentar a capacidade de processamento, tornar o sistema mais amigável e melhorar a apresentação dos resultados. Na Tabela 2, apresentam-se essas alterações.

A estrutura de cálculos do SIAT é a mesma do CERVATANA, ou seja, a entrada dos dados (12 variáveis) é feita quadrícula por quadrícula, que imediatamente é classificada em uma das quatro classes possíveis: $\mathrm{S}_{1}, \mathrm{~S}_{2}, \mathrm{~S}_{3}$ e N. A interface com o SIG permite que cada variável seja associada a um Plano de Informação (P.I.) de toda área, no formato raster, num total de 12 P.I's. Após as codificações, os atributos de cada quadrícula, em cada P.I., o sistema executa os cruzamentos necessários, resultando na ordenação das quatro classes possíveis para cada quadrícula. A articulação dos dados e planos de informações está representada na Figura 3. 
TABELA 1. Alterações introduzidas no aplicativo original.

\begin{tabular}{|c|c|c|c|}
\hline Variável/Parâmetro - CERVATANA & Peso & Variável/Parâmetro - SIAT V.1.0 & Peso \\
\hline Fator Relevo - Declividade & & Fator Relevo - Declividade & \\
\hline Nula ou Suave $(<7 \%)$ & 1 & Nula ou Suave $(<5 \%)$ & 1 \\
\hline Ligeira ou Moderada (7-15\%) & 2 & Ligeira ou Moderada (5-10\%) & 2 \\
\hline Forte $(15-30 \%)$ & 3 & Forte $(10-20 \%)$ & 3 \\
\hline Escarpada $(>30 \%)$ & 4 & Muito Forte (> 20\%) & 4 \\
\hline Fator Solo - Profundidade Útil & & Fator Solo - Profundidade Útil & \\
\hline Elevada $(>75 \mathrm{~cm})$ & 1 & Elevada $(>200 \mathrm{~cm})$ & 1 \\
\hline Moderada $(50-75 \mathrm{~cm})$ & 2 & Moderada $(200-80 \mathrm{~cm})$ & 2 \\
\hline Escassa $(25-50 \mathrm{~cm})$ & 3 & $\operatorname{Rasa}(80-40 \mathrm{~cm})$ & 3 \\
\hline Superficial $(<25 \mathrm{~cm})$ & 4 & Superficial $(<40 \mathrm{~cm})$ & 4 \\
\hline Fator Solo - Tipo de Textura & & Fator Solo - Tipo de Textura & \\
\hline Equilibrada & 1 & Equilibrada & 1 \\
\hline Ligeira ou Pesada & 2 & Argilosa & 2 \\
\hline & 3 & Arenosa & 3 \\
\hline Fator Solo - Pedregosidade e/ou Afloramento & & Fator Solo - Pedregosidade e/ou Afloramento & \\
\hline Nula ou Ligeira $(<15 \%)$ & 1 & Nula ou Ligeira $(<10 \%)$ & 1 \\
\hline Ligeira a Moderada (15-40\%) & 2 & Ligeira a Moderada (10-20\%) & 2 \\
\hline Elevada $(>40 \%)$ & 3 & Elevada $(>20 \%)$ & 3 \\
\hline Fator Solo - Tipo de Drenagem & & Fator Solo - Tipo de Drenagem & \\
\hline Boa & 1 & Boa & 1 \\
\hline Moderada & 2 & Moderada & 2 \\
\hline Deficiente ou Excessiva & 3 & Deficiente ou Excessiva & 3 \\
\hline Fator Solo - Salinidade Total & & Fator Solo - Acidez/pH & \\
\hline Nula ou Ligeira $(<4$ mmhos/cm) & 1 & Nula ou Ligeira $(7,0-6,0)$ & 1 \\
\hline Moderada (4-8 mmhos/cm) & 2 & Moderada $(6,0-5,0)$ & 2 \\
\hline Elevada $(8-12 \mathrm{mmhos} / \mathrm{cm})$ & 3 & Elevada $(5,0-4,0)$ & 3 \\
\hline Muito Elevada (> $12 \mathrm{mmhos} / \mathrm{cm}$ ) & 4 & Muito Elevada $(<4,0)$ & 4 \\
\hline Fator Risco à Erosão - Erodibilidade & & Fator Risco à Erosão - Erodibilidade & \\
\hline Ligeira & 1 & Ligeira & 1 \\
\hline Moderada & 2 & Moderada & 2 \\
\hline Elevada & 3 & Elevada & 3 \\
\hline Fator Risco à Erosão - Declividade & & Fator Risco à Erosão - Declividade & \\
\hline Baixa $<15 \%$ & 1 & Baixa $<10 \%$ & 1 \\
\hline Média $15-30 \%$ & 2 & Média $10-20 \%$ & 2 \\
\hline Alta $>30 \%$ & 3 & Alta $>20 \%$ & 3 \\
\hline Fator Risco à Erosão - Densidade Vegetação & & Fator Risco à Erosão - Densidade Vegetação & \\
\hline Elevada & 1 & Elevada $(>80 \%)$ & 1 \\
\hline Moderada & 2 & Moderada $(80-40 \%)$ & 2 \\
\hline Nula & 3 & Baixa $(<40 \%)$ & 3 \\
\hline Fator Risco à Erosão - Erosividade & & Fator Risco à Erosão - Erosividade & \\
\hline Ligeira $(<150)$ & 1 & Ligeira $(<700)$ & 1 \\
\hline Moderada (150-200) & 2 & Moderada (700-725) & 2 \\
\hline Forte $(200-300)$ & 3 & Forte $(725-750)$ & 3 \\
\hline Muito Forte $(>300)$ & 4 & Muito Forte (> 750) & 4 \\
\hline Variável/Parâmetro - CERVATANA & Peso & Variável/Parâmetro - SIAT V.1.0 & Peso \\
\hline Fator Deficiência Bioclimática & & Fator Deficiência Bioclimática & \\
\hline Grau de Umidade (Ih=P/ETP) & & Grau de Umidade (AD=P-ETP) & \\
\hline Suficiente $(=>1)$ & 1 & Excesso $(>1.500)$ & 1 \\
\hline Moderado (1-1/2) & 2 & Suficiente $(1.500-350)$ & 2 \\
\hline
\end{tabular}



Escasso (1/2-1/3)
Muito Escasso $(=<1 / 3)$
Fator Deficiência Bioclimática
Risco de Geadas
Nulo ou Ligeiro $(=<2)$
Ligeiro a Moderado (2-5)
Elevado $(=>5)$

3 Moderado (350-200)

$4 \quad$ Escasso $(<200)$

3

. Fator Deficiência Bioclimática

\section{Risco de Geadas}

Nulo ou Ligeiro $(<2)$

Ligeiro a Moderado (2-4)

Elevado (>4)

3

TABELA 2. Alterações na estrutura do programa.

\begin{tabular}{|l|l|l|}
\hline \multirow{2}{*}{ Item } & \multicolumn{1}{|c|}{ Aplicativo } \\
\cline { 2 - 3 } & \multicolumn{1}{|c|}{ CERVATANA } & \multicolumn{1}{c|}{ SIAT V.1.0 } \\
\hline Linguagem & \multicolumn{1}{|c|}{ GW - BASIC } & $\begin{array}{l}\text { CLIPPER e C } \\
\text { variável já definidos }\end{array}$ \\
\hline Interface com usuário & Comandos & $\begin{array}{l}\text { Senha em dois níveis: Administrador e } \\
\text { Usuário }\end{array}$ \\
\hline Entrada de dados & Não pede senha & $\begin{array}{l}\text { Armazena os dados dos solos em banco } \\
\text { de dados }\end{array}$ \\
\hline Avaliação de terras & $\begin{array}{l}\text { Avalia dados de todos os solos no no } \\
\text { banco de dados }\end{array}$ \\
\hline Resultados & Avalia um solo de cada vez & Em tela e em relatório \\
\hline Utilitários & Apenas em tela & $\begin{array}{l}\text { Backup, restore e indexação de banco } \\
\text { de dados }\end{array}$ \\
\hline
\end{tabular}

\section{Planos de Informações}

\begin{tabular}{|l|l|l|l|l|}
\hline \multicolumn{1}{|c|}{ BASE DE DADOS } \\
\hline - Base Cartográfica \\
- Limites/divisas \\
- Hidrografia/drenagem \\
- Sistema viário \\
- Cidades e vilas \\
- Curvas de nivel \\
- Pedologia \\
- Mapa de solos \\
- Informações qualitativas \\
- Informações quantitativas \\
- Cobertura do Terreno \\
- Vegetação natural \\
- Agricultura \\
- Uso urbano \\
- Outros \\
- Clima \\
- Precipitação - mensal/anual \\
- Temperatura/geada
\end{tabular}

FIGURA 3. Articulação dos dados pelo SIAT. 


\section{Interface com o IDRISI}

A interface engloba três etapas: do IDRISI para o SIAT; execução do SIAT; do SIAT para o IDRISI e espacialização dos resultados, sendo seu objetivo fornecer ligação entre o SIAT e o SIG.

\section{Modificações introduzidas no SIAT V. 1.0 para o SIAT V. 1.4}

Para a área selecionada, os dados relacionados com o Fator Solo (profundidade efetiva, textura, pedregosidade, drenagem interna e acidez $=\mathrm{pH}$ ); Fator Relevo (declividade); Fator Erosão (erodibilidade do solo, declividade, densidade vegetativa, erosividade da chuva); Fator de Deficiência Bioclimática (geada, água disponível) foram armazenados numa base de dados apropriada e todos os planos georreferenciados. As modificações introduzidas são apresentadas na Tabela 3.

\section{Nos parâmetros quantitativos}

TABELA 3. Alterações introduzidas na nova versão do SIAT.

\begin{tabular}{|c|c|c|c|}
\hline Variável/Parâmetro - SIAT V.1.0 & Peso & Variável/Parâmetro - SIAT V.1.4. & Peso \\
\hline Fator Relevo - Declividade & & Fator Relevo - Declividade & \\
\hline Nula ou Suave $(<5 \%)$ & 1 & Nula ou Suave $(<6 \%)$ & 1 \\
\hline Ligeira ou Moderada (5-10\%) & 2 & Ligeira ou Moderada (6-10\%) & 2 \\
\hline Forte $(10-20 \%)$ & 3 & Forte $(10-15 \%)$ & 3 \\
\hline Muito Forte (> 20\%) & 4 & Muito Forte (> 15\%) & 4 \\
\hline Fator Solo - Profundidade Útil & & Fator Solo - Profundidade Útil & \\
\hline Elevada $(>200 \mathrm{~cm})$ & 1 & Elevada $(>200 \mathrm{~cm})$ & 1 \\
\hline Moderada $(200-80 \mathrm{~cm})$ & 2 & Moderada $(200-80 \mathrm{~cm})$ & 2 \\
\hline Rasa $(80-40 \mathrm{~cm})$ & 3 & $\operatorname{Rasa}(80-40 \mathrm{~cm})$ & 3 \\
\hline Superficial $(<40 \mathrm{~cm})$ & 4 & Superficial $(<40 \mathrm{~cm})$ & 4 \\
\hline Fator Solo - Tipo de Textura & & Fator Solo - Tipo de Textura & \\
\hline Equilibrada & 1 & Equilibrada & 1 \\
\hline Argilosa & 2 & Argilosa & 2 \\
\hline Arenosa & 3 & Arenosa & 3 \\
\hline Fator Solo - Pedregosidade e/ou Afloramento & & Fator Solo - Pedregosidade e/ou Afloramento & \\
\hline Nula ou Ligeira $(<10 \%)$ & 1 & Nula ou Ligeira $(<10 \%)$ & 1 \\
\hline Ligeira a Moderada (10-20\%) & 2 & Ligeira a Moderada (10-20\%) & 2 \\
\hline Elevada $(>20 \%)$ & 3 & Elevada $(>20 \%)$ & 3 \\
\hline Fator Solo - Drenagem Interna & & Fator Solo - Drenagem Interna & \\
\hline Boa & 1 & Boa & 1 \\
\hline Moderada & 2 & Moderada & 2 \\
\hline Deficiente ou Excessiva & 3 & Deficiente ou Excessiva & 3 \\
\hline Fator Solo - Acidez/pH & & Fator Solo - Acidez/pH & \\
\hline Nula ou Ligeira $(7,0-6,0)$ & 1 & Nula ou Ligeira $(7,0-6,5)$ & 1 \\
\hline Moderada $(6,0-5,0)$ & 2 & Moderada $(6,5-5,8)$ & 2 \\
\hline Elevada $(5,0-4,0)$ & 3 & Elevada $(5,8-5,0)$ & 3 \\
\hline Muito Elevada $(<4,0)$ & 4 & Muito Elevada $(<5,0)$ & 4 \\
\hline Fator Risco à Erosão - Erodibilidade & & Fator Risco à Erosão - Erodibilidade & \\
\hline Ligeira & 1 & Ligeira & 1 \\
\hline Moderada & 2 & Moderada & 2 \\
\hline Elevada & 3 & Elevada & 3 \\
\hline Fator Risco à Erosão - Declividade & & Fator Risco à Erosão - Declividade & \\
\hline Baixa $(<10 \%)$ & 1 & Baixa $(<10 \%)$ & 1 \\
\hline Média $(10-20 \%)$ & 2 & Média (10-15\%) & 2 \\
\hline Alta $(>20 \%)$ & 3 & Alta $(>15 \%)$ & 3 \\
\hline
\end{tabular}




\begin{tabular}{|c|c|c|c|}
\hline Variável/Parâmetro - SIAT V.1.0 & Peso & Variável/Parâmetro - SIAT V.1.4 & Peso \\
\hline Fator Risco à Erosão - Densidade Vegetação & & Fator Risco à Erosão - Densidade Vegetação* & \\
\hline Elevada $(>8 \%)$ & 1 & Elevada $\mathrm{C}<0,01$ & 1 \\
\hline Moderada $(80-40 \%)$ & 2 & Moderada $0,01 \leq \mathrm{C}<0,045$ & 2 \\
\hline Baixa $(<40 \%)$ & 3 & Baixa $C \geq 0,045$ & 3 \\
\hline Fator Risco à Erosão - Erosividade & & Fator Risco à Erosão - Erosividade** & \\
\hline Ligeira $(<700)$ & 1 & Ligeira $(<575)$ & 1 \\
\hline Moderada (700-725) & 2 & Moderada (575-625) & 2 \\
\hline Forte $(725-750)$ & 3 & Forte $(600-625)$ & 3 \\
\hline Muito Forte $(>750)$ & 4 & Muito Forte $(\geq 625)$ & 4 \\
\hline Fator Deficiência Bioclimática & & Fator Deficiência Bioclimática & \\
\hline Grau de Umidade & & Grau de Umidade & \\
\hline Excesso $(>1500)$ & 1 & Excesso $(\geq 1350)$ & 1 \\
\hline Suficiente (1500-350) & 2 & Suficiente (1350-200) & 2 \\
\hline Moderado (350-200) & 3 & Moderado (200-100) & 3 \\
\hline Escasso $(<200)$ & 4 & Escasso $(<100)$ & 4 \\
\hline Fator Deficiência Bioclimática & & Fator Deficiência Bioclimática & \\
\hline Geadas (dias/ano) & & Geadas (dias/ano) & \\
\hline$<2$ & 1 & $<2$ & 1 \\
\hline $2-4$ & 2 & $2-4$ & 2 \\
\hline$>4$ & 3 & $>4$ & 3 \\
\hline
\end{tabular}

*Fator C da USLE: C $<0,001$ - Floresta, Cerradão; 0,001 $\leq$ C $<0,045$ - Reflorestamento, Pastagens, Fruticultura; C $\geq 0,045$

- Culturas anuais, solo nu.

**Ei $=89,823\left(\mathrm{r}^{2} / \mathrm{P}\right)^{0,759}$, em que, $\mathrm{r}$ - média da precipitação num determinado mês, e $\mathrm{P}$ - precipitação total no ano.

\section{Na interface com o IDRISI}

Na primeira versão do SIAT, a interface permitia comunicação bastante simples com o IDRISI. Os dados entravam no sistema pela digitalização dos códigos das quadrículas de cada plano temático, o que se revelou um processo demorado e tedioso.

Na nova versão, a estrutura de armazenamento dos dados em cada plano temático continua sendo um quadriculado. No entanto, a interface desenvolvida permite a utilização dos recursos do SIG, como, por exemplo, a transformação de vetorial para raster e vice-versa. Esse recurso facilitou e acelerou o processo de entrada dos dados, permitindo que mapas armazenados no banco de dados do SIG possam ser exportados para o SIAT e que os resultados desse possam ser encaminhadas ao SIG e tratados com todas as funções disponíveis, como, por exemplo, edição de mapa, Display com cores de mapa na tela, impressão de mapa, descrição completa do tema, etc.

\section{Validação do SIAT V. 1.4}

Como já comentado, o SIAT é um modelo empírico e como tal precisa ser comparado com uma situação real, para que seja possível avaliar a respectiva precisão. Ajustando-se os intervalos das variáveis de entrada, procura-se chegar o mais próximo possível da realidade.

Conforme comentam PESSOA et al.(1997b), a utilização de modelos pressupõe o conhecimento de suas limitações e dos problemas relativos a sua utilização. A comparação com um sistema real que o represente na escala do objeto de estudo, apoiado por trabalhos de campo, é uma alternativa válida para validação dos resultados.

Para garantir a confiabilidade do processo, podem-se utilizar métodos matemáticos adequados, como é o caso da matriz de erro ou de contingência (STORY \& CONGALTON, 1986). Os erros que podem aparecer, nesse caso, podem ser de omissão e de inclusão, sendo, no primeiro caso, referentes a 
amostras de certa classe dos dados SIAT que não foram classificados como tal e, no segundo caso, referentes a amostras de uma classe dos dados erroneamente classificados.

A amostragem delineada consiste de um número determinado de unidades de amostragem que podem ser pontos, linhas ou áreas. Nesse caso, foi utilizada uma grade, em que cada célula possui as dimensões de 2,0 x 2,0 mm que, para a escala 1:50.000, corresponde a uma área, no terreno, de 1,0 ha $(100 \times 100 \mathrm{~m})$.

Uma vez estabelecida a matriz, algumas medidas podem ser realizadas. De acordo com VEREGIN (1989), a proporção de células classificadas corretamente é calculada dividindo-se o número de amostras classificadas, posicionadas na diagonal da matriz, pelo número total de células avaliadas. Na avaliação da eficiência de cada calibração do sistema, a estatística de precisão/erro foi feita mediante uma matriz de contingência. Para um limite de confiança não menor que $85 \%$, utilizouse da seguinte relação:

$$
\mathrm{p}=\tilde{\mathrm{p}}-1,645 \sqrt{\frac{\tilde{\mathrm{p}}-\tilde{\mathrm{q}}}{\mathrm{n}}}+\frac{50}{\mathrm{n}}
$$

em que,

p - precisão do mapa SIAT para uma dada calibração, \%;

$\mathrm{p}$ - porcentagem correta geral, \%;

$\tilde{\mathrm{q}}=100-\tilde{\mathrm{p}}, \mathrm{e}$

$\mathrm{n}$ - tamanho da amostra.

Nesse caso, utilizou-se da sistemática da capacidade de uso como referência, recomendada por LEPSCH et al. (1983), sendo o trabalho executado de modo tradicional. A comparação foi feita em área especialmente selecionada, no médio curso do Rio Jacaré-Pepira (Figura 1).

\section{RESULTADOS E DISCUSSÃO}

A utilização prática da primeira versão do SIAT identificou duas fontes de imprecisões: o cálculo da erosividade e da densidade da vegetação. Nessa nova versão, mudou-se a maneira pela qual tais variáveis eram calculadas.

Aproveitou-se, também, para melhorar os intervalos das variáveis de entrada, procurando aproximar os resultados obtidos daqueles resultados da classificação de referência.

Para comparar a classificação executada com o SIAT V.1.4, com a classificação de referência, foram aplicados testes comparativos, em especial a Matriz de Contingência. Na Tabela 4, apresentamse os resultados obtidos.

TABELA 4. Resultados do teste comparativo

\begin{tabular}{cccc}
\hline Classificação & Erro Médio de Omissão (\%) & Erro Médio de Inclusão (\%) & Porcentagem de Semelhança \\
\hline SIAT 1.0 & 16,4 & 14,2 & 86,3 \\
SIAT 1.4 & 4,8 & 4,1 & 96,8 \\
\hline
\end{tabular}

Os resultados revelam que, para a área de estudo, a versão original do SIAT apresentou baixa precisão. A nova versão, por outro lado, apresentou resultados bastante satisfatórios, considerando a escala dos mapas-fonte, na escala 1:50.000, ou reambulados para essa escala. 
Isso pode ser explicado, principalmente, pela forma de calcular a erosividade. Na versão inicial do SIAT, essa variável era calculada grosseiramente, a partir de uma carta em escala muito pequena, por interpolação gráfica dos pontos de interesse. Ao calcular a erosividade, utilizando equação adequada com dados locais de chuvas, a precisão melhorou sensivelmente. Essa alternativa permite, também, que o SIAT possa ser ajustado facilmente para regiões que não contem com Cartas de Erosividade, mas que disponham de dados de chuvas.

A modificação na maneira como a densidade da vegetação era calculada, substituída pelo Fator C da USLE, confere também maior precisão ao método, diminuindo a subjetividade.

É importante esclarecer que, sendo um modelo empírico, alterações nos intervalos das variáveis podem ser feitas tantas vezes quantas forem necessárias, até que se atinja a máxima precisão possível, comparativamente à classificação de terras usada como referência. A precisão da classificação pela nova versão do SIAT pode ser considerada alta, provavelmente pelo fato de o sistema apresentar os resultados em apenas quatro classes.

Diante da forte influência do clima, especialmente das chuvas, fica evidente que é praticamente impossível um único ajuste, mesmo para o Estado de São Paulo. Avaliações qualitativas dos domínios morfoclimáticos paulistas indicam que haveria no mínimo três ajustes: a) Região Serrana do Norte do Estado; b) Região Costeira; c) Restante do território.

Como o sistema é aberto, é permitido ao usuário aumentar ou diminuir o número de variáveis (Planos de Informações), aumentar ou diminuir o número de classes em cada variável, substituir uma variável por outra, mais adequada à região e alterar a pontuação atribuída a critérios subjetivos. A premissa do SIAT, à semelhança do MicroLEIS/CERVATANA, é de ser um sistema simples e fácil de ajustar e aplicar nas mais diferentes regiões brasileiras.

A quantidade de alterações introduzidas na nova versão de um software é indicada, aproximadamente, pela numeração que recebe. Neste caso, o SIAT passa de Versão 1.0 para Versão 1.4 e pode ser obtida em www.rc.unesp.br/igce/ceapla/biblioteca/softwares/siat.html.

\section{CONCLUSÕES}

As modificações introduzidas no sistema melhoram a precisão da classificação de terras.

O SIAT V.1.4, pela simplicidade, pode ser de grande utilidade no planejamento.

Essa simplicidade permite que o sistema possa ser costumizado para diferentes regiões.

\section{REFERÊNCIAS}

ALMEIDA, C.L.F.; OLIVEIRA, J.B.; PRADO, H. Levantamento pedológico semidetalhado do Estado de São Paulo, quadrícula de Brotas. Campinas: Instituto Agronômico, 1981. Escala 1:100.000.

ANDERSON, L.T. Seven methods for calculating land capability/suitability. Chicago: American Planning Association, 1987. 20 p. (Report, 402).

ASSAD, E.D. Sistemas de informações geográficas - aplicações na agricultura. Brasília: EMBRAPASPI/CPAC, 1998. 434 p.

BAUDRY, J. Interactions between agricultural and ecological systems at the landscape level. Agriculture, Ecosystems and Environment, Amsterdam, v.27, n.2, p.119-30, 1989.

EMPRESA BRASILEIRA DE PESQUISA AGROPECUÁRIA. Sistema brasileiro de classificação de solos. Rio de Janeiro, 1999. 412 p. 
FERNANDES, E.N.; FERNANDES FILHO, E.N.; SILVA, E.; SILVA, C.A.B.; RICARDO, J.F. EROSYS: Sistema de apoio ao processo de avaliação de impactos ambientais de atividades agropecuárias. Revista Brasileira de Agroinformática, Londrina, v.4, n.1, p.1-12, 2002.

FULFARO, V.J.; LANDIN, P.M.B.; ELLERT, N. A tectônica das Serras de Santana e São Pedro (Serra Geral). In: CONGRESSO BRASILEIRO DE GEOLOGIA, 21., 1967, Curitiba. Anais... Curitiba: Sociedade Brasileira de Geologia, 1967. p.198-205.

GARCIA, G.J.; ESPINDOLA, C.R. SIAT - Sistema de Avaliação de Terras. Revista Brasileira de Engenharia Agrícola e Ambiental, Campina Grande, v.5, n.2, p.223-8, 2001.

INTERNATIONAL INSTITUTE FOR AERIAL SURVEY AND EARTH SCIENCE. The LIS/GIS Iinformation System. Enshede, 1990. 10 p.

KEULEN, H. Data and models in land resource management. ITC Journal, Enschede, v.12, n.3, p.3638, 1990.

KLINGEBIEL, A.A.; MONTGOMERY, P.H. Land capability classification. Washington: Soil Conservation Service, 1961. 21 p. (Handbook, 210).

KOFFLER, N.F. Sistema de análise ambiental para planejamento agrícola. Versão 2.0. Rio Claro: CEAPLA, 1993. 35 p.

LAI, P. Feasability of geographic information systems approach for natural resource management. Environment Management, San Francisco, v.14, n.1, p.73-80, 1990.

LEPSCH, I.F.; BELINAZZI, R.; BERTOLINI, D.; ESPINDOLA, C.R. Manual para levantamento utilitário do meio físico e classificação de terras. Campinas: Sociedade Brasileira de Ciência do Solo, 1983. $175 \mathrm{p}$.

LOMBARDI NETO, F.; BERTONI, J.E. Erodibilidade dos solos paulistas. Campinas: IAC, 1975. 34 p. (Boletim Técnico, 27).

MacClEAN, A.L.; D’AVELLO, T.P.; SHETRON, S.G. Digital soil maps in a GIS. Photogrammetric Engineering and Remote Sensing, Falls Church, v.59, n.3, p.223-8, 1993.

OLIVEIRA, J.B.; BERG, M. Aptidão agrícola das terras do Estado de São Paulo. Quadrícula de Araras. Campinas: IAC, 1985. 60 p.

PESSOA, M.C.; LUCHIARI, A.J.; FERNANDES, E.N.; LIMA, M.A. Principais modelos matemáticos e simuladores utilizados para análise de impactos ambientais nas atividades agrícolas. Jaguariúna: EMBRAPA/CNPMA, 1997. 83 p.

PINTO, S.A.F. Contribuição metodológica para análise de indicadores de erosão utilizando técnicas de sensoriamento remoto, geoprocessamento e modelo preditivo. 1995. 136 f. Tese (Livre-Docência em Cartografia) - Instituto de Geociências e Ciências Exatas, Universidade Estadual Paulista, Rio Claro, 1995.

PRADO, H.; OLIVEIRA, J.B.; ALMEIDA, C.L.F Levantamento pedológico semidetalhado do Estado de São Paulo, quadrícula de São Carlos. Campinas: Instituto Agronômico, 1987. Escala 1:100.000.

RAMALHO FILHO, A.; PEREIRA, E.G.; BEEK, K.J. Sistema de avaliação da aptidão agrícola das terras. Brasília: EMBRAPA, 1978. 70 p.

ROSA, D.; MORENO, J.A.; GARCIA, L.V.; ALMORZA, J. A microcomputer-based mediterranean land evaluation system. Soil Use and Management, Madison, v.8, n.1, p.89-96, 1992. 
SIGRH - Sistema Integrado de Gerenciamento de Recursos Hídricos de São Paulo. Disponível em: $<$ http://www.sigrh.sp.gov>. Acesso em: fevereiro 2004.

SOARES, P.C.; LANDIN, P.M.B. Depósitos cenozóicos na região Centro-Sul do Brasil. Notícia Geomorfológica, Campinas, v.16, n.31, p.17-39, 1976.

STELLE, J.G. Soil survey interpretation and its use. Rome: FAO, 1967. 34 p. (Soils Bulletin, 8). STORY, M.; CONGALTON, R.G. Accuracy assessment: A user's perspective. Photogrammetric Engineering and Remote Sensing, Falls Church, v.52, n.3, p.397-9, 1986.

TIM, V.S. Emerging technologies for modeling research. Transactions of the ASAE, St. Joseph, v.39, n.4, p.465-76, 1996.

TUCCI, C.E.M. Modelos hidrológicos. Porto Alegre: Ed. UFRGS, 1998. 240 p.

VEREGIN, H. A taxonomy of error in spatial databases. Santa Barbara: Nacional Center for Geographic Information Analysis, 1989. 113 p. 